\title{
Erratum
}

TSG Tijdschr Gezondheidswet (2021) 99:80

https://doi.org/10.1007/s12508-021-00305-y

Q

Check for
updates

\section{Erratum to: Werken vanuit plekken in het echte leven}

\section{Een kansrijk sociaal-ruimtelijk raamwerk}

Ant Lettinga - Martian Slagter · Ellis Merkelijn · Louise Meijering

Published online: 31 mei 2021

(C) The Author(s) 2021

\section{Erratum to:}

TSG Tijdschr Gezondheidswet 2021

https://doi.org/10.1007/s12508-020-00286-4

De naam van de laatste auteur was onjuist vermeld: dit moet Louise Meijering zijn.

De online versie van de originele bijdrage vindt $u$ onder https://doi.org/10.1007/s12508-020-00286-4.

A. Lettinga $(\bowtie) \cdot$ M. Slagter

Afdeling Epidemiologie, Universitair Medisch Centrum

Groningen, Groningen, Nederland

a.t.lettinga@umcg.nl

E. Merkelijn

Merkelijn Coaching, Groningen, Nederland

L. Meijering

Faculteit Ruimtelijke Wetenschappen, Universiteit

Groningen, Groningen, Nederland 